\title{
Correction to: 90 years of thermal analysis as a control tool in the melting of cast iron
}

\author{
*Doru Michael Stefanescu ${ }^{1}$, Ramon Suarez ${ }^{2,3}$, and Sung Bin Kim ${ }^{4}$ \\ 1. The Ohio State University, Columbus, $\mathrm{OH}$ and The University of Alabama, Tuscaloosa, AL, USA \\ 2. IK4-Azterlan, Durango (Bizkaia), Spain \\ 3. Veigalan Estudio 2010, Durango (Bizkaia), Spain \\ 4. AnyCasting Software Co., Ltd, Seoul, S. Korea
}

Copyright $(\mathcal{C}$ Foundry Journal Agency and Springer Nature Singapore Pte Ltd.

Correction to: CHINA FOUNDRY journal, Vol. 17, Issue No. 2 (2020): 69-84

https://doi.org/10.1007/s41230-020-0039-x

Following the publication of the article by Stefanescu et al. ${ }^{[1]}$, missing citation was discovered. To make the article more comprehensive and complete, the authors propose to publish a correction. And the authors would like to apologize for any inconvenience caused to the readers by these changes in the paper. The corresponding corrections are shown below:

1. In the second paragraph of Section 1 Principles of thermal analysis, a reference (Kuehn U, 2005) was missed and should be cited in the middle of the first sentence of this paragraph. Because of that the first sentence in the second paragraph of Section 1 (page 70) should be read:

More recently, Kuehn (Kuehn U, 2005) developed, and Anjos et al. ${ }^{[10]}$ used, a dual-cup TA system where in one chamber the hot junction of the thermocouple was placed at the center, and in the other chamber the hot junction was close to the wall of the cup, as presented in Fig. 2.

2. Accordingly, the name of the dual-cup thermal ananlysis mold should be corrected. The corrected legend of Fig. 2 is given below:

Fig. 2: Kuhen AccuVo ${ }^{\mathrm{TM}}$ dual-cup thermal analysis mold: (a) external view of the cup; (b) image from the internal sample body shape; (c) top view of the bottom half of the cup showing the disposition of the two thermocouples ${ }^{[10] "}$.

Omitted reference in the list:

Kuehn U. Probengefaess zur Analyse von Schmelzen (Sample vessel for the analysis of melts). German Patent, 10209427, 2 Aug. 2005.

\section{Reference}

[1] Stefanescu D M, Suarez R, and Kim S B. 90 years of thermal analysis as a control tool in the melting of cast iron. China Foundry, 2020, 17(2): 69-84. https://doi.org/10.1007/s41230-020-0039-X.

Correspondence author: Doru Michael Stefanescu

E-mail: stefanescu.1@osu.edu 